\title{
Potential for acrylamide formation in potatoes: data from the 2003 harvest
}

\section{Journal Article}

\section{Author(s):}

Amrein, Thomas M.; Schönbächler, Barbara; Rohner, Fabian; Lukac, Helen; Schneider, Hanna; Keiser, Andreas; Escher, Felix; Amadò, Renato

\section{Publication date:}

2004-11

\section{Permanent link:}

https://doi.org/10.3929/ethz-b-000038423

\section{Rights / license:}

$\underline{\text { In Copyright - Non-Commercial Use Permitted }}$

Originally published in:

European Food Research and Technology 219(6), https://doi.org/10.1007/s00217-004-1025-z 
Thomas M. Amrein • Barbara Schönbächler •

Fabian Rohner • Helen Lukac • Hanna Schneider •

Andreas Keiser • Felix Escher • Renato Amadò

\section{Potential for acrylamide formation in potatoes: data from the 2003 harvest}

Received: 2 July 2004 / Published online: 22 September 2004

(C) Springer-Verlag 2004

\begin{abstract}
Reducing sugars, free amino acids, and the potential for acrylamide formation were determined in more than 50 potato samples from the 2003 harvest in Switzerland. The reducing sugar content strongly correlated with acrylamide, whereas no correlation was found between acrylamide and free asparagine or the pool of free amino acids. The reducing sugar contents and the acrylamide potentials were higher in most of the cultivars tested than in the samples from 2002. This was probably due to the hot and dry summer of 2003. Monitoring sugars and amino acids during heating at $120{ }^{\circ} \mathrm{C}$ and $180{ }^{\circ} \mathrm{C}$ showed that glucose and fructose reacted much faster than sucrose and the amino acids. Glutamine was consumed to a larger extent than any of the other amino acids. During prolonged storage, the reducing sugars decreased considerably while only moderate changes in the free amino acids were observed. Altogether, glucose and fructose remain the critical factors for acrylamide formation in potatoes and represent the most feasible way of reducing the formation of acrylamide in potato products.
\end{abstract}

Keywords Potato - Acrylamide - Reducing sugars - Free asparagine $\cdot$ Free amino acids

\section{Introduction}

Acrylamide is neurotoxic, and is classified as probably carcinogenic to humans (group 2A) by the IARC [1], and its detection in a broad range of heated foods at concentrations exceeding $1000 \mu \mathrm{g} / \mathrm{kg}$ [2] caused world-wide

T. M. Amrein · B. Schönbächler · F. Rohner · H. Lukac ·

H. Schneider · F. Escher · R. Amadò (

Institute of Food Science and Nutrition,

Swiss Federal Institute of Technology (ETH),

Zurich, Switzerland

e-mail: renato.amado@ilw.agrl.ethz.ch

Fax: +41-1632-1123

A. Keiser

Swiss College of Agriculture,

Zollikofen, Switzerland concern. Acrylamide is formed concurrently to the Maillard reaction [3,4] from a reducing sugar and the free amino acid asparagine, which delivers the backbone for the acrylamide molecule $[5,6]$.

Since potatoes naturally contain large amounts of free asparagine and reducing sugars [7, 8], fried and baked potato products such as French fries, chips (American terminology), baked potatoes, and hash browns show the highest acrylamide contents in foods, sometimes exceeding $3000 \mu \mathrm{g} / \mathrm{kg}[2,9,10,11]$. In order to decrease the acrylamide contents of these products, various approaches were employed: the frying process was optimized and strictly controlled [12]; citric acid was added [13, 14]; and asparaginase was successfully applied [6]. However, in practice, any technological effort to limit the acrylamide formation in heated potato products is in vain if the raw material is not suitable. The glucose and fructose concentration largely determines the formation of acrylamide in potatoes $[7,15]$ and the appropriate selection of the raw material in terms of reducing sugar content is crucial to reduce the acrylamide content $[12,16]$. Therefore, a detailed knowledge of the composition of the raw material and the influence of the harvest and storage are of fundamental importance.

The aim of the present study was to investigate potato samples from the 2003 harvest in Switzerland in terms of reducing sugar content, free amino acids, and the potential for acrylamide formation, and to check the interrelations between these parameters. Results from over 50 samples from 15 different cultivars were obtained and compared to an analogous study made in 2002 [7]. Furthermore, changes of potato components during standardized heat treatments, as well as during prolonged storage, were monitored.

\section{Materials and methods}

Collection of potato samples

Samples of cultivars Agria, Appell, Bintje, Charlotte, Desirée, Eba, Naturella, Nicola, Panda, and Santana were collected in Switzer- 
land by the Swiss College of Agriculture (Zollikofen, Switzerland), from August to September 2003, according to a well-defined sampling plan: 55 tubers from 55 plants were taken from each field, giving a total of about $5 \mathrm{~kg}$ per sample. The potatoes were part of a three year on-farm experiment employing different farming systems (organic, integrated, conventional), focusing on quality aspects and monitoring all relevant data concerning crop rotation, cultivation technique, site parameters, and tuber quality.

Samples of the cultivars Erntestolz, Hermes, Lady Claire, Markies, and Panda were obtained from Zweifel Pomy-Chips AG (Spreitenbach, Switzerland). In addition, some samples were purchased at local supermarkets (cultivars Agata, Appell, Bintje, Stella, Nicola, and Urgenta). All samples were stored at $9{ }^{\circ} \mathrm{C}$ and 95-98\% relative humidity from harvest until analysis (November and December 2003).

\section{Sample preparation}

At least 15 tubers of a given sample were washed, and after the water was dripped off, cut lengthwise. One half of each tuber was grated. The grated material was thoroughly mixed and used for all analyses. For the determination of sugars and free amino acids, $50.00 \mathrm{~g}$ of grated potato were homogenized (Polytron, Kinematica, Lucerne, Switzerland) with $100.00 \mathrm{~g}$ of deionized water.

\section{Analysis of acrylamide}

The potential for acrylamide formation was determined according to Biedermann et al [9]: $20 \mathrm{~g}$ of grated potato was spread on a grid and heated in a $\mathrm{GC}$ oven at $120^{\circ} \mathrm{C}$ for 40 minutes. After measuring the residual weight (the dry matter), water (to a total weight of $20 \mathrm{~g}$ ) and $500 \mu \mathrm{g} / \mathrm{kg}$ of internal standards were added. The internal standards were ${ }^{13} \mathrm{C}_{3}$-acrylamide (CIL, Andover, Massachusetts, USA) and methacrylamide (Fluka, Buchs, Switzerland), both dissolved in methanol (Fluka). Acrylamide was determined with a GC-MS method as described in [17]. GC-MS involved an 8000series gas chromatograph with on-column injector (Fisons Instruments, Milan, Italy) coupled with a SSQ 710 quadrupole mass spectrometer (Finnigan Mat., San Jose, USA). The precolumn (TSP deactivated, i.d. $0.53 \mathrm{~mm}$ ) and the separation column (BGB Wax, $12 \mathrm{~m}$, i.d. $0.25 \mathrm{~mm}$ ) were both from BGB Analytik (Böckten, Switzerland). GC and MS conditions were as described in [17]. Results were calculated as the potential of acrylamide formation referring to fresh weight.

\section{Measurement of free amino acids}

$7.5 \mathrm{~g}$ of the potato slurry was weighed (under stirring) into a $100 \mathrm{~mL}$ flask, and then $1 \mathrm{~mL}$ of internal standard solution (DLnorleucine, $500 \mathrm{mg}$ in $100 \mathrm{~mL}$ bi-distilled water, Fluka) and about $50 \mathrm{~mL}$ of $0.1 \mathrm{M} \mathrm{HCl}$ (Fluka) were added. $5 \mathrm{~mL}$ of Carrez I $(150 \mathrm{~g}$ of $\mathrm{K}_{4}\left[\mathrm{Fe}(\mathrm{CN})_{6}\right] \cdot 3 \mathrm{H}_{2} \mathrm{O}$ per liter, Fluka) and Carrez II (300 g of $\mathrm{ZnSO}_{4} \cdot 7 \mathrm{H}_{2} \mathrm{O}$ per liter, Fluka) solutions were added and the mixture was vigorously shaken. Foam was broken with $50 \mu \mathrm{L}$ of 1 -octanol (Fluka) and the volume was adjusted to $100 \mathrm{~mL}$ with $0.1 \mathrm{M} \mathrm{HCl}$ (Fluka). After filtration (Schleicher \& Schuell, Dassel, Germany), the samples were diluted $1+4$ with $0.16 \mathrm{M}$ lithium citrate buffer (pH 2.2, PVP Physiological; Laborservice Onken, Gründau, Germany) and thoroughly mixed. Diluted samples were filtered through a $0.45 \mu \mathrm{m}$ HPLC membrane filter (Titan; Infochroma, Zug, Switzerland) and subjected to analysis by cation-exchange chromatography followed by post-column derivatization with ninhydrin (Biochrom 30, Biochrom, Cambridge, UK), using the physiological system (Biochrom) as described by the producer. The injection volume was $50 \mu \mathrm{L}$ and quantification was achieved by comparing with both an external standard and the internal standard.
Determination of sugars

$54 \mathrm{~g}$ of the potato slurry was weighed (under stirring) into a $250 \mathrm{~mL}$ flask and about $150 \mathrm{~mL}$ of de-ionized water was added. After Carrez clarification (5 mL of each Carrez I and II solution), the foam was broken with a few drops of 1-octanol (Fluka), the pH was adjusted to 7 with a few drops of $\mathrm{KOH}$ solution (4 mol/L, Fluka) and the volume was adjusted to $250 \mathrm{~mL}$ with deionized water. After filtration (Schleicher \& Schuell), the fructose, glucose, and sucrose were determined enzymatically using the kit from Scil Diagnostics (Martinsried, Germany).

Statistical analysis

Statistical analysis was carried out using Microsoft Excel 2002 and NCSS 2001 Number Cruncher statistical systems (Kaysville, Utah, USA).

\section{Results and discussion}

\section{Tuber composition and acrylamide formation}

Besides the known acrylamide precursors (glucose, fructose, and free asparagine), the whole pool of free amino acids was determined in all potato samples (Table 1). Repeated analysis of the same potato sample (cultivar Charlotte, $n=4$ ) gave a mean acrylamide potential of $327 \mu \mathrm{g} / \mathrm{kg}$ with a relative standard deviation of $3.5 \%$, highlighting the good repeatability of this procedure and confirming that the variation from the procedure is much smaller than the variation between different potato samples.

The values for free amino acids in Table 1 were calculated by comparison with the external standard. Values obtained from the internal standard were similar: for asparagine, the values determined with the internal standard were $7 \%$ higher than those from the external standard, which was due to a slightly smaller recovery of the internal standard norleucine compared to asparagine. This effect was also seen for other free amino acids but less pronounced. The values in Table 1 are within the range reported in other studies $[7,8,18,19,20,21]$. The potentials for acrylamide formation and the reducing sugar contents varied much more widely than the free amino acids. Sugar contents are more influenced by cultivar, climate, and storage conditions, and so vary more than the free amino acids; this has also been observed in other studies [7, 8, 15]. Asparagine, glutamine, aspartic acid, and glutamic acid were the main free amino acids and comprised, on average, $77 \%$ of the free amino acid pool, with the largest contribution coming from asparagine (39$64 \%$ ). In addition, the following free amino acids were detected: alanine, valine, isoleucine, leucine, tyrosine, phenylalanine, $\gamma$-amino butyric acid, histidine, and arginine.

Statistical analysis revealed that the only significant difference occurred between the acrylamide potentials of cultivar Eba and Panda. However, Nicola clearly had a higher potential than Panda, but due to the small number of samples ( $n=3$ for Nicola) it was not detected as being 
Table 1 Potentials for acrylamide formation, reducing sugars, and free amino acids in the potato samples analysed

\begin{tabular}{lllllllll}
\hline Cultivar & $n$ & $\begin{array}{l}\mathrm{AA}^{\mathrm{a}} \\
{[\mu \mathrm{g} / \mathrm{kg}]}\end{array}$ & $\begin{array}{l}\text { Glc }+\mathrm{Fru}^{\mathrm{b}} \\
{[\mathrm{mg} / \mathrm{kg}]}\end{array}$ & $\begin{array}{l}\mathrm{Asn}^{\mathrm{c}} \\
{[\mathrm{mg} / \mathrm{kg}]}\end{array}$ & $\begin{array}{l}\mathrm{Gln}^{\mathrm{d}} \\
{[\mathrm{mg} / \mathrm{kg}]}\end{array}$ & $\begin{array}{l}\mathrm{Glu}^{\mathrm{e}} \\
{[\mathrm{mg} / \mathrm{kg}]}\end{array}$ & $\begin{array}{l}\text { Asp } \\
{[\mathrm{mg} / \mathrm{kg}]}\end{array}$ & $\begin{array}{l}\text { Total free amino } \\
\mathrm{acids}[\mathrm{mg} / \mathrm{kg}]\end{array}$ \\
\hline Agria & 7 & $703(79 \%)$ & $1020(73 \%)$ & $2959(13 \%)$ & $892(16 \%)$ & $435(65 \%)$ & $427(27 \%)$ & $5946(15 \%)$ \\
Appell & 1 & 1602 & 2574 & 3390 & 1588 & 296 & 253 & 7338 \\
Bintje & 7 & $930(45 \%)$ & $1676(55 \%)$ & $3200(12 \%)$ & $1080(18 \%)$ & $559(23 \%)$ & $473(16 \%)$ & $7152(15 \%)$ \\
Charlotte & 7 & $579(108 \%)$ & $877(96 \%)$ & $3640(8 \%)$ & $1541(16 \%)$ & $492(29 \%)$ & $467(17 \%)$ & $8003(8 \%)$ \\
Desirée & 1 & 1239 & 1872 & 3568 & 1024 & 377 & 437 & 7233 \\
Eba & 6 & $1553(96 \%)$ & $2802(67 \%)$ & $2543(12 \%)$ & $1216(16 \%)$ & $407(33 \%)$ & $318(13 \%)$ & $5840(11 \%)$ \\
Erntestolz & 2 & $194(76 \%)$ & $232(70 \%)$ & $3538(15 \%)$ & $927(0.2 \%)$ & $514(4 \%)$ & $453(13 \%)$ & $6661(16 \%)$ \\
Hermes & 2 & $791(85 \%)$ & $904(45 \%)$ & $4438(45 \%)$ & $960(34 \%)$ & $231(101 \%)$ & $446(2 \%)$ & $7417(33 \%)$ \\
Lady Claire & 2 & $105(7 \%)$ & $157(25 \%)$ & $3165(0.4 \%)$ & $1484(4 \%)$ & $479(6 \%)$ & $510(7 \%)$ & $6815(1 \%)$ \\
Markies & 2 & $494(84 \%)$ & $552(34 \%)$ & $4392(27 \%)$ & $1579(24 \%)$ & $458(4 \%)$ & $407(12 \%)$ & $8337(22 \%)$ \\
Naturella & 1 & 3823 & 6734 & 3494 & 1184 & 389 & 319 & 6778 \\
Nicola & 3 & $1518(3 \%)$ & $2587(41 \%)$ & $3444(25 \%)$ & $1141(46 \%)$ & $411(24 \%)$ & $399(25 \%)$ & $7160(18 \%)$ \\
Panda & 5 & $209(111 \%)$ & $351(98 \%)$ & $2727(22 \%)$ & $799(27 \%)$ & $555(18 \%)$ & $538(26 \%)$ & $5995(22 \%)$ \\
Santana & 1 & 386 & 1215 & 2518 & 1078 & 354 & 291 & 6171 \\
\hline
\end{tabular}

${ }^{\mathrm{a}}$ acrylamide, ${ }^{\mathrm{b}}$ glucose + fructose,${ }^{\mathrm{c}}$ asparagine, ${ }^{\mathrm{d}}$ glutamine, ${ }^{\mathrm{e}}$ glutamic acid, ${ }^{\mathrm{f}}$ aspartic acid; mean values are used in the table; relative standard deviation in brackets; samples obtained from supermarkets are not included

significantly different. A similar situation occurred for glucose and fructose. The only statistically significant difference in the free asparagine content was found between cultivars Charlotte and Eba. More significant differences were found for aspartic acid content: Eba contained least and was different from Charlotte, Bintje, and Panda (which was different from Eba and Agria). The pool of free amino acids was highest in cultivar Charlotte and significantly different from Eba and Agria. In 2003, many samples showed a "germination/shooting" which was probably due to the hot and dry summer. This phenomenon was strongest for Eba (significantly different from Panda, Nicola, Charlotte, and Agria), followed by Bintje (significantly different from Panda, Charlotte, and Agria) and Agria (significantly different from Bintje and Eba). This is probably a major cause of the elevated sugar contents in these three cultivars compared to the 2002 harvest $[7,22]$. Cultivars used for the production of potato chips (particularly Lady Claire and Panda) were generally low in reducing sugars, but the low number of samples for these cultivars allowed no statistical distinction from other cultivars. However, it is well known that such cultivars are bred and selected for low sugar content.

Samples obtained from supermarkets generally contained more reducing sugars: the mean content was $6097 \mathrm{mg} / \mathrm{kg}(n=6)$ with a maximum of $8542 \mathrm{mg} / \mathrm{kg}$ (cultivar Nicola). A sample of cultivar Bintje contained $6585 \mathrm{mg} / \mathrm{kg}$ of reducing sugars, which is far above the mean in Table 1. Free asparagine ranged from 2103 to $4470 \mathrm{mg} / \mathrm{kg}$ (mean $3174 \mathrm{mg} / \mathrm{kg}$ ) which is within the range of the samples in Table 1 . These results indicate that probably all the samples from the supermarkets had been stored at low temperatures, which led to the wellknown phenomenon of "cold temperature sweetening" [21]. The effect of the elevated sugar contents on the potential for acrylamide formation was drastic: the potentials ranged from 1494 to $5585 \mu \mathrm{g} / \mathrm{kg}$ with a mean of $3737 \mu \mathrm{g} / \mathrm{kg}$, which is high compared to the values shown in Table 1. Therefore, commercial storage of the potatoes

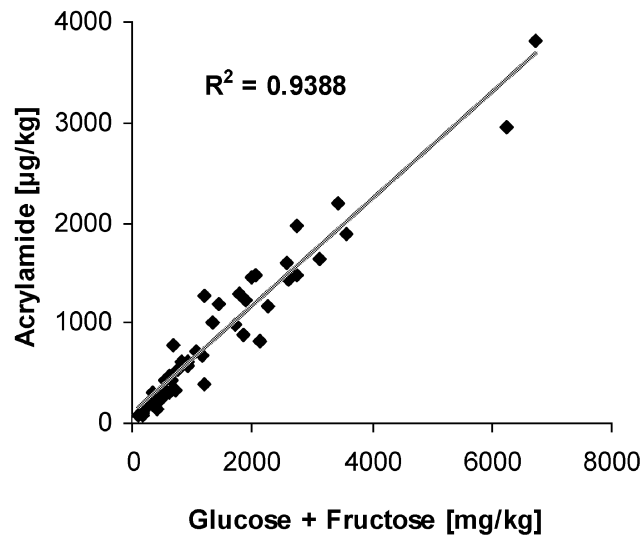

Fig. 1 Correlation between the acrylamide formation potential and the reducing sugar concentration

from the 2004 harvest must be adapted in order to limit the release of reducing sugars during storage.

All measured components were checked for correlations to the acrylamide potential (data from Table 1 only). Figure 1 shows the strong correlation between reducing sugars and the acrylamide potential. Glucose and fructose content obviously determines the acrylamide formation in potatoes, which has also been shown in other studies [7, $15,16,23]$.

The following components also correlated strongly with the potential of acrylamide formation: fructose $\left(R^{2}=0.9404\right)$, glucose $\left(R^{2}=0.9245\right)$, and the formula $(0.5 \times$ glucose+fructose $) \times$ asparagine $\left(R^{2}=0.9211\right)$. The contents of free asparagine $\left(R^{2}=0.0085\right)$, free glutamine $\left(R^{2}=\right.$ $0.0043)$, free glutamic acid $\left(R^{2}=0.0800\right)$, free aspartic acid $\left(R^{2}=0.1792\right)$, total free amino acids $\left(R^{2}=0.0057\right)$, the contributions of each of these free amino acids to the pool of free amino acids $\left(R^{2}<0.083\right)$, the concentration of any minor free amino acid $\left(R^{2}<0.14\right)$, and the dry matter $\left(R^{2}=0.1195\right)$ all did not correlate with acrylamide formation. Glucose strongly correlated with fructose $\left(R^{2}=0.9523\right)$, as observed in other studies [7, 8, 15]. 


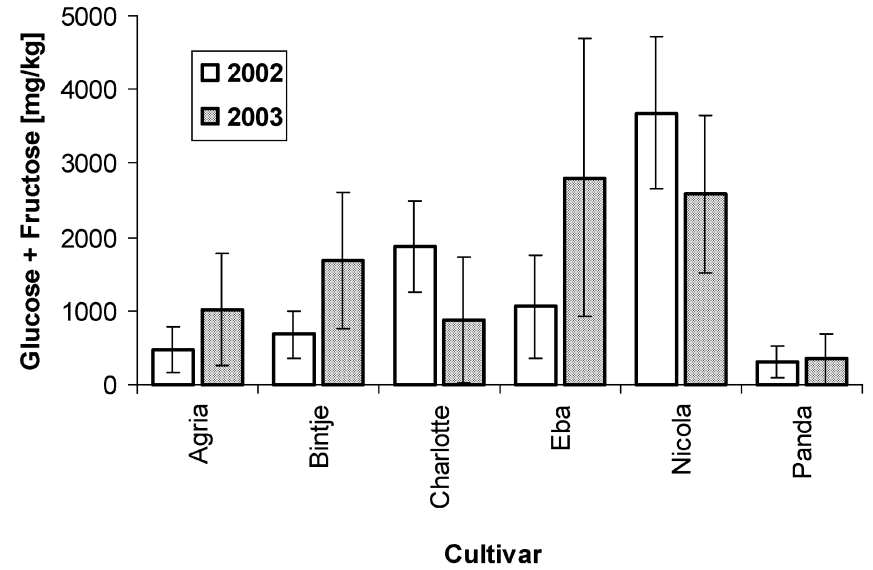

Fig. 2 Concentrations of reducing sugars in different potato cultivars from the 2002 and 2003 harvests (error bars are \pm standard deviation; $n$ for 2003 see Table 1; $n$ for 2002: Agria: $n=22$, Bintje: $n=12$, Charlotte: $n=8$, Eba: $n=8$, Nicola: $n=3$, Panda: $n=4$ )

Overall, these results show that the reducing sugar content determines acrylamide formation. There is no general correlation between acrylamide and any of the free amino acids, which fully confirms the results from the study of the 2002 harvest [7]. Combination of the data from 2002 and 2003 showed no correlation between Nfertilisation and acrylamide potential $\left(R^{2}=0.038\right)$, free asparagine, glucose, or fructose, results that were also found for the 2003 data alone. In fact, cultivar and climate have been shown to be much more important to reducing sugar concentration than any kind of fertilization [24]. Asparagine is much more abundant than glucose and fructose (Table 1), reacts much more slowly than these sugars (see the results below), and is therefore not limiting - in fact the correlation between reducing sugars and the acrylamide potential turned out to be stronger if free asparagine was not taken into account. Data from French fries [15] showed no correlation between the acrylamide content and the concentration of free asparagine in the raw potatoes $\left(R^{2}=0.0001\right)$, whereas acrylamide correlated with reducing sugars $\left(R^{2}=0.8182\right)$, which corroborates our findings.

\section{Comparison of the 2002 and 2003 harvests}

Data obtained from the harvest of 2003 were compared with those from the harvest of 2002 [7], and the reducing sugar contents of the most important cultivars from both years are shown in Fig. 2. In Switzerland, as on the European continent in general [25], the summer of 2003 was extraordinary hot: the mean temperature of the summer months was over five standard deviations higher than the average of the period 1864-2000, and so it was the hottest summer in the past 500 years [26]. The mean temperature in the daytime for August 2003 was $5{ }^{\circ} \mathrm{C}$ higher than that for August 2002, and similar differences were recorded for other summer months in Switzerland [27, 28]. Potatoes from 2003 showed strongly elevated sugar contents, and the differences between the cultivars were less distinct than in 2002. Charlotte showed a lower sugar content in 2003 because the Charlotte samples in 2002 were stored at a lower temperature [7]. The differences for cultivar Nicola probably just reflect normal variations. The strongest increases in reducing sugars were found in cultivars Eba $(+165 \%)$, Bintje $(+146 \%)$, and Agria $(+113 \%)$, and all of these were significant. These cultivars showed the most pronounced sprouting and the formation of a second tuber generation before harvest. Bintje and Eba are known to be particularly sensitive to stress, like heat and drought [22]. This explains the pronounced increase of reducing sugars in these three cultivars. Panda potatoes still exhibited low sugar contents, while they were again very high in cultivar Nicola, as observed in 2002 [7]. The potential for acrylamide formation in 2003 showed exactly the same pattern, because it strongly correlated with the average reducing sugar content $\left(R^{2}=0.9787\right)$.

No significant differences in the free asparagine contents were found between the two harvests. This shows that reducing sugars are much more influenced by cultivars and season, whereas free asparagine is relatively stable. The extraordinarily hot and dry climate in 2003 was probably a major cause for the elevated levels of reducing sugars and, as a consequence, for the increased acrylamide potentials in some potato cultivars from the 2003 harvest. Climate, in particular temperature, has a strong influence on sugar metabolism in potatoes: reducing sugars can vary by more than a factor of four for a given cultivar between different harvests [24]. High temperature $\left(29^{\circ} \mathrm{C}\right)$ decreased tuber growth [29] and led to a stronger incorporation of ${ }^{14} \mathrm{C}$ into sucrose and less incorporation into starch [30]. The callus tissue of cultivar Russet Burbank was shown to contain more reducing sugars after eight weeks at $30^{\circ} \mathrm{C}$ compared to $20^{\circ} \mathrm{C}$ [31]. Therefore, the climatic situation, the harvest conditions, and the storage conditions must all be taken into account if a reduction in the levels of acrylamide in potato products is demanded. Since the year-to-year variability of the climate is expected to increase in the future [26], this could make the provision of potatoes with low sugar contents more difficult.

Changes in potato components during prolonged storage

The changes in tuber composition during prolonged storage were monitored in three samples (cultivars Agria, Charlotte, and Bintje). Figure 3 shows that reducing sugars in the sample of cultivar Agria decreased steadily during the first 180 days of storage, while asparagine did not change a lot $-a$ result that has also been reported in other studies $[8,20]$. The changes in reducing sugar strongly correlated with the acrylamide potential $\left(R^{2}=0.9557\right)$. In the other two cultivars, the sugars decreased in a similar way, but the asparagine and total free amino acid contents both increased after about 180 days, which could be due to proteinase activity [20]. The decreasing level of reducing 


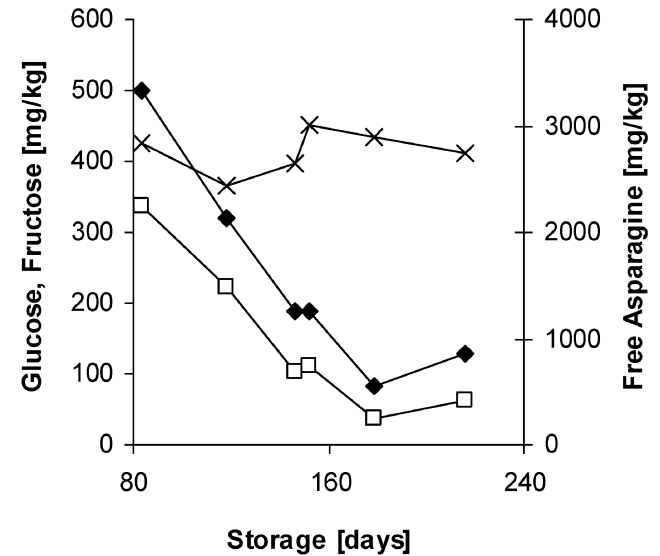

Fig. 3 Changes in tuber components in a sample of cultivar Agria during prolonged storage. Diamonds: glucose; squares: fructose; $x$ : free asparagine (concentrations refer to fresh weight)

sugars during storage at $8{ }^{\circ} \mathrm{C}$ is a clear advantage in terms of acrylamide. However, after approximately 150 days all of the samples started to sprout, which is a disadvantage. To clarify the effect of storage at elevated temperatures $\left(\geq 8{ }^{\circ} \mathrm{C}\right)$ in depth, several projects are currently ongoing in Switzerland to check the suitability of the available cultivars for this storage technique [32]. Storage at $8{ }^{\circ} \mathrm{C}$ of suitable potato cultivars, eventually combined with the application of sprout inhibitors, might be a way to reduce the acrylamide content of fried or roasted potato products by supplying raw material with a low sugar content.

Changes in potato components during the determination of the acrylamide formation potential

Levels of acrylamide, sugars and free amino acids in a potato sample of cultivar Bintje heated to $120{ }^{\circ} \mathrm{C}$ for 40 minutes were determined in order to monitor their reactivity and consumption. Glucose reacted slightly faster than fructose (Fig. 4). Both reducing sugars had disappeared almost completely after 40 minutes, whereas sucrose did not react as expected, which explains why there is no correlation between the sucrose content and the potential for acrylamide formation [7]. The apparent increase in the sucrose content could be due to inhomogeneities in the sample or to a slight overestimation during the enzymatic determination because of the very low glucose content.

The changes in the free amino acids are shown in Fig. 5. After 40 minutes, $74 \%$ of the free asparagine was still present. Asparagine obviously reacts much more slowly than the reducing sugars (Fig. 4), and only a small part of it is consumed during the heat treatment. The glutamine content decreased more than any of the free amino acids: after 40 minutes only $40 \%$ of the initial content was found and its proportion within the amino acid pool was significantly smaller than the other free amino acids. Threonine, serine, isoleucine, tyrosine, phenylalanine, $\gamma$-amino butyric acid, and proline behaved in a

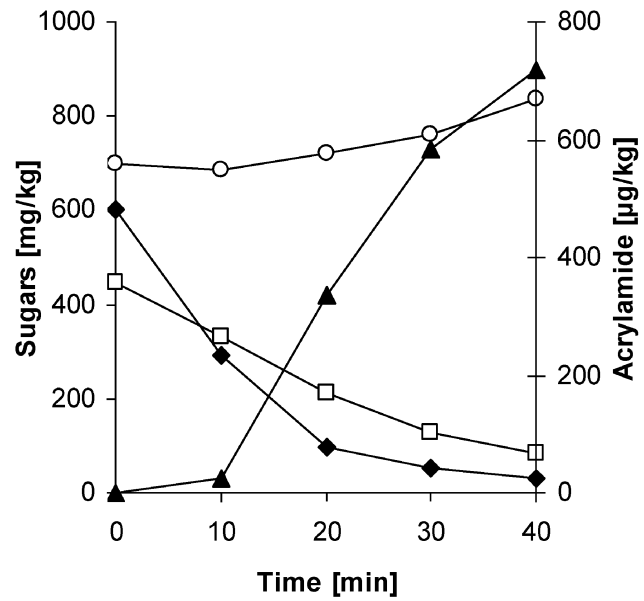

Fig. 4 Changes in sugar content and acrylamide formation during the determination of the potential for acrylamide formation (40 min at $120{ }^{\circ} \mathrm{C}$ ). Triangles: acrylamide; diamonds: glucose; squares: fructose; circles: sucrose (concentrations refer to fresh weight)

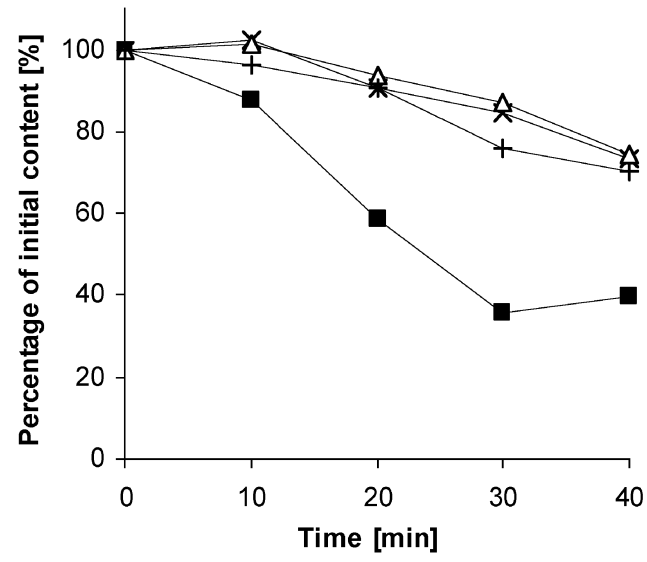

Fig. 5 Changes in the proportions of the four major free amino acids during the determination of the potential for acrylamide formation $\left(40 \mathrm{~min}\right.$ at $\left.120{ }^{\circ} \mathrm{C}\right) . \times$ : Asparagine; triangles: aspartic acid; crosses: glutamic acid; squares: glutamine

similar way to asparagine, and they all decreased by approximately $30 \%$. In the first 10 minutes virtually no acrylamide was formed, but afterwards the acrylamide content increased in an exponential manner, reaching $718 \mu \mathrm{g} / \mathrm{kg}$ after 40 minutes. Similar behavior for the acrylamide concentration in grated potato has been described by Biedermann et al [9].

In addition to the standard heat treatment, one experiment with heating at $180{ }^{\circ} \mathrm{C}$ for 20 minutes was carried out, and samples were taken every five minutes. Figure 6 shows the time courses of the sugar and acrylamide concentrations. More acrylamide was formed after 10 minutes than after 20 minutes at $120^{\circ} \mathrm{C}$. Subsequently the increase was less pronounced, which might be due to enhanced elimination of acrylamide or lack of reducing sugars. Glucose and fructose were depleted after 10 minutes, and in contrast to heating at $120{ }^{\circ} \mathrm{C}$, sucrose was consumed as well, but much more slowly than glucose and fructose: 


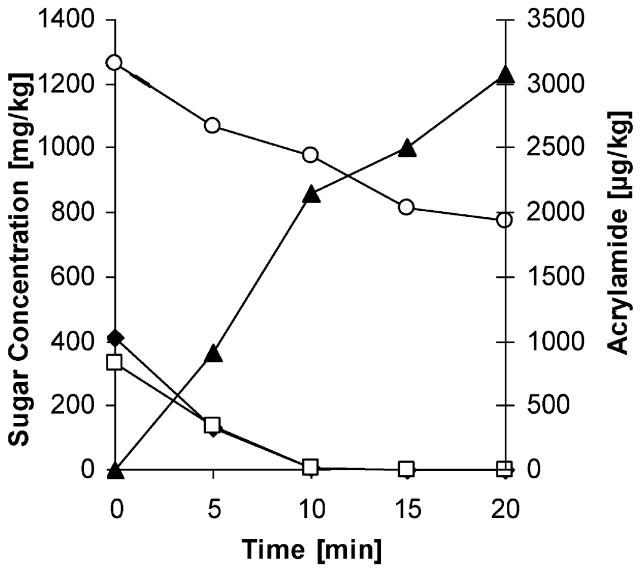

Fig. 6 Changes in sugar contents during heating at $180{ }^{\circ} \mathrm{C}$. Diamonds: glucose; squares: fructose; circles: sucrose; triangles: acrylamide (concentrations refer to fresh weight)

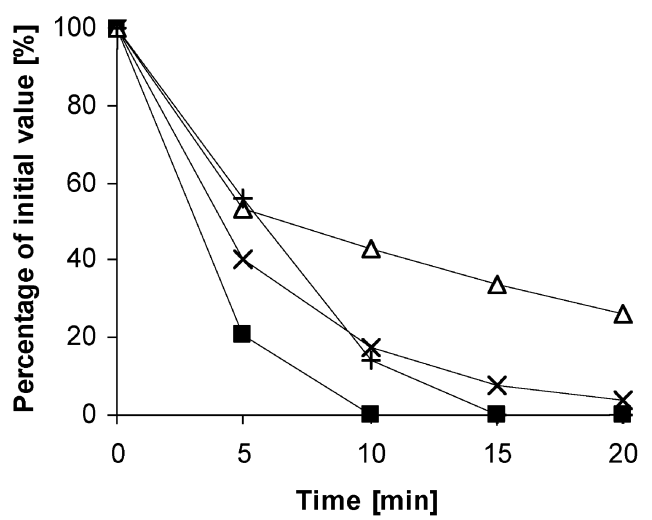

Fig. 7 Changes in free amino acids during heating at $180{ }^{\circ} \mathrm{C}$ for 20 min. $\times$ : Asparagine; triangles: aspartic acid; crosses: glutamic acid; squares: glutamine

after 20 minutes $61 \%$ of the initial sucrose content was still found. Therefore, sucrose might be of some importance for acrylamide formation in strongly fried and roasted potato products. In fact, sucrose was suggested to contribute to nonenzymatic browning in potato chips [33], correlated with the acrylamide content of French fries [15], and it formed some acrylamide when pyrolyzed with asparagine [4]. However, the higher reactivity of glucose and fructose surpasses the influence of sucrose, and the reducing sugar level remains the key factor for acrylamide formation in potato products.

At $180{ }^{\circ} \mathrm{C}$ the changes in free amino acids were more pronounced than at $120{ }^{\circ} \mathrm{C}$ (Fig. 7). After 20 minutes, only $4 \%$ of the initial amount of asparagine was found, while glutamine was completely depleted after 10 minutes, confirming its higher reactivity. Asparagine and glutamic acid behaved in similar ways: in the first 10 minutes about $85 \%$ was consumed, and after 20 minutes they were depleted. Aspartic acid, leucine, isoleucine, tyrosine, and proline were consumed to a considerably smaller amount: after 20 minutes at $180{ }^{\circ} \mathrm{C}, 20$ $30 \%$ of their initial content was still present.
Aspartic acid and isoleucine are known to react much more slowly with carbonyls than other amino acids [34], which explains part of this observation. Glutamine was shown to be completely deamidated at $110{ }^{\circ} \mathrm{C}$ after $2 \mathrm{~h}$, whereas glutamic acid, aspartic acid, and asparagine were stable, which explains the large losses of glutamine during both heat treatments [35]. At $180{ }^{\circ} \mathrm{C}$ ammonia is also released from asparagine and aspartic acid [35]. The release of ammonia from free amino acids could be an important factor for the acrylamide formation in heated potato products, because ammonia strongly enhances acrylamide formation [36]. However, no correlation was found between any of the free amino acids or the pool of free amino acids with the acrylamide formation potential, and reducing sugars turned out to be the key factor for acrylamide formation in potato products, as shown in other studies $[7,9,15,16]$.

Acknowledgements We thank Zweifel Pomy-Chips AG, Spreitenbach, Switzerland for supplying potato samples. Financial support was provided by the Swiss Federal Office for Public Health (BAG), the Federation of Swiss Food Industries (FIAL), COOP Switzerland, and Cooperative Migros.

\section{References}

1. IARC (1994) Acrylamide. International Agency for Research on Cancer, Lyon, France

2. Tareke E, Rydberg P, Karlsson P, Eriksson S, Törnqvist M (2002) J Agr Food Chem 50:4998-5006

3. Mottram DS, Wedzicha BL, Dodson AT (2002) Nature 419:448-449

4. Stadler RH, Blank I, Varga N, Robert F, Hau J, Guy PA, Robert MC, Riediker S (2002) Nature 419:449-450

5. Yaylayan VA, Wnorowski A, Locas CP (2003) J Agr Food Chem 51:1753-1757

6. Zyzak DV, Sanders RA, Stojanovic M, Tallmadge DH, Eberhart BL, Ewald DK, Gruber DC, Morsch TR, Strothers MA, Rizzi GP, Villagran MD (2003) J Agr Food Chem 51:47824787

7. Amrein TM, Bachmann S, Noti A, Biedermann M, Barbosa MF, Biedermann-Brem S, Grob K, Keiser A, Realini P, Escher F, Amadò R (2003) J Agr Food Chem 51:5556-5560

8. Olsson K, Svensson R, Roslund CA (2004) J Sci Food Agr 84:447-458

9. Biedermann M, Biedermann-Brem S, Noti A, Grob K (2002) Mitt Geb Lebensm Unters Hyg 93:653-667

10. Becalski A, Lau BPY, Lewis D, Seaman SW (2003) J Agr Food Chem 51:802-808

11. Rosén J, Hellenäs KE (2002) Analyst 127:880-882

12. Grob K, Biedermann M, Biedermann-Brem S, Noti A, Imhof D, Amrein T, Pfefferle A, Bazzocco D (2003) Eur Food Res Technol 217:185-194

13. Gama-Baumgartner F, Grob K, Biedermann M (2004) Mitt Geb Lebensm Unters Hyg 95:110-117

14. Jung MY, Choi DS, Ju JW (2003) J Food Sci 68:1287-1290

15. Becalski A, Lau BPY, Lewis D, Seaman SW, Hayward S, Sahagian M, Ramesh M, Leclerc Y (2004) J Agr Food Chem 52:3801-3806

16. Biedermann-Brem S, Noti A, Grob K, Imhof D, Bazzocco D, Pfefferle A (2003) Eur Food Res Technol 217:369-373

17. Biedermann M, Biedermann-Brem S, Noti A, Grob K, Egli P, Mändli H (2002) Mitt Geb Lebensm Unters Hyg 93:638-652

18. Eppendorfer WH, Bille SW (1996) J Sci Food Agr 71:449-458

19. Haase NU, Weber L (2003) Food Agric Env 1:80-81 
20. Brierley ER, Bonner PLR, Cobb AH (1996) J Sci Food Agr 70:515-525

21. Coffin RH, Yada RY, Parkin KL, Grodzinski B, Stanley DW (1987) J Food Sci 52:639-645

22. Münster J, Reust W (1977) Revue Suisse Agr 9:53-58

23. Chuda Y, Ono H, Yada H, Ohara-Takada A, Matsuura-Endo C, Mori M (2003) Biosci Biotech Bioch 67:1188-1190

24. Putz B (2004) Kartoffelbau 55:188-192

25. Lauterbacher J, Dietrich D, Xoplaki E, Grosjean M, Wanner H (2004) Science 303:1499-1503

26. Schär C, Vidale PL, Lüthi D, Frei C, Häberli C, Liniger MA, Appenzeller C (2004) Nature 427:332-336

27. MeteoSchweiz (2003) Homepage. http://www.meteoschweiz.ch

28. MeteoSchweiz (2004) Homepage. http://www.meteoschweiz.ch
29. Lafta AM, Lorenzen JH (1995) Plant Physiol 109:637-643

30. Wolf S, Marani A, Rudich J (1991) J Exp Bot 42:619-625

31. Hagen SR, Muneta P (1993) Plant Cell Tiss Org 32:115121

32. Hebeisen T (2004) Personal communication. Agroscope FAL Reckenholz; Swiss Federal Research Station for Agroecology and Agriculture, Zurich, Switzerland

33. Leszkowiat MJ, Barichello V, Yada RY, Coffin RH, Lougheed EC, Stanley DW (1990) J Food Sci 55:281-282, 284

34. Piloty M, Baltes W (1979) Z Lebensm Unters For 168:368-373

35. Sohn M, Ho CT (1995) J Agr Food Chem 43:3001-3003

36. Amrein TM, Schönbächler B, Escher F, Amadò R (2004) J Agr Food Chem 52:4282-4288 